\title{
Clinical Management of Pediatric Genomic Testing
}

\author{
Ingrid A. Holm
}

Published online: 9 August 2014

(C) Springer Science + Business Media New York 2014

\begin{abstract}
As sequencing becomes integrated into clinical medicine, many complex ethical questions arise regarding the return of genomic information, especially in pediatrics. Issues center on the best interests of the child, particularly in return of information about adult-onset conditions. These include the child's future autonomous decisionmaking and access to knowledge about treatable conditions, the child in the family unit, and benefit to family members of learning information which could impact them personally. This article first discusses the framework for returning genomic information, and then ethical issues regarding return of results. Finally, it discusses potential harms and benefits, while recognizing that little is known about what these actually are. A new era of genomic information is in its infancy; handling genomic information in a way that provides patients and their families with knowledge that is helpful without causing distress is the greatest challenge.
\end{abstract}

Keywords Genetics - Exome sequencing - Genome sequencing - Incidental finding - Secondary finding · Primary finding $\cdot$ Pediatrics $\cdot$ Families $\cdot$ Ethics $\cdot$ Return of results

\footnotetext{
I. A. Holm ( $\square)$

Division of Genetics and Genomics and The Manton Center for Orphan Disease Research, Boston Children's Hospital, 3 Blackfan Circle, CLSB 15022, Boston, MA 02115, USA e-mail: ingrid.holm@childrens.harvard.edu

I. A. Holm

Department of Pediatrics, Harvard Medical School, Boston, MA, USA
}

\section{Introduction}

As sequencing technologies have evolved rapidly over the last 5 years and whole exome/genome sequencing has become a commodity, the ethical issues around the use of genetic sequencing in health care and research have come to the forefront. Nowhere are these issues more complex than in pediatrics. This review will focus on the controversies surrounding the disclosure of results arising from whole exome/genome sequencing in pediatrics, focusing on the risk of disclosure of adult-onset conditions. The ethical issues include the preservation of the child's future autonomous decision-making, protection of the child's privacy, potential for discrimination (against the child or family) in employment or disability and long-term care insurance, potential stigmatization or labeling of the child, psychological risks associated with possible parental overprotection or "vulnerable child syndrome," health and psychological implications for the child's siblings, translation of future health-risk information into preventive health behaviors, continuity of care and of the health record to ensure information is appropriately and accurately disclosed to the patient or to future clinicians, determination of what health risk information to make available to the child and at what age, and both the child's and parents' "right not to know."

The cost for sequencing a human exome or genome has drastically decreased from over $\$ 2$ billion in 2001 when the first human sequence was published $[1,2]$ to several $\$ 1,000$ in 2014. As a result, performing whole exome or genome sequencing for clinical purposes is now financially feasible. In pediatrics, sequencing may be performed to make a genetic diagnosis in a child with an unknown but likely genetic condition or to determine if a child is at risk for a genetic condition that runs in the family. The task is to sort 
through gene variants to find the variant of interest, which in clinical medicine is the disease-causing variant and in research is the variant related to the indication for the sequencing. Variants are generally classified as pathogenic, likely pathogenic, or variant of unknown significance (VUS). Genes are generally classified as a gene known to cause disease, a gene that is known but is not known to cause disease, or an unknown gene. The American College of Medical Genetics and Genomics (ACMG) has developed a decision tree for variant reporting.

What about the rest of the genome? The genome is sequenced because one is looking for something, but there are many variants within the genome that may have meaning for the individual. In 2006, Kohane [3] coined the term "the incidentalome" stating that "This phenomenon of possible incidental genomic findings-the incidentalo$m e$-threatens to undermine the promise of molecular medicine." [3].

\section{Definitions}

Genetic findings can be divided into several categories. The primary finding is the indication for the sequencing. In clinical sequencing, the indication for the sequencing is the primary condition being evaluated. In the research context, the indication for the sequencing is the research question for which sequencing is being performed. In either case, the primary genetic finding is the gene that one is looking for.

Secondary or Incidental findings are genetic findings of clinical significance that are unrelated to the initial reason for the sequencing. The Presidential Commission for the Study of Bioethical Issues in their report "Anticipate and Communicate: Ethical Management of Incidental and Secondary Findings in the Clinical, Research, and Directto-Consumer Contexts" [4] defines genetic findings unrelated to the initial reason for the sequencing that are unexpected as incidental finding and those that are deliberately searched for as secondary finding. On the other hand the "ACMG recommendations for reporting of incidental findings in clinical exome and genome sequencing" [5] defines incidental finding as "the results of a deliberate search for pathogenic or likely pathogenic alterations in genes that are not apparently relevant to a diagnostic indication for which the sequencing test was ordered.". This latter definition has been controversial as the usual definition of an incidental finding as unexpected is not consistent with a "deliberate search" for pathogenic findings unrelated to the diagnostic indication for which sequencing was ordered $[6,7]$. For the purposes of this discussion, I will use the Presidential Commission definition that incidental findings are considered as those that arise unexpectedly and secondary findings are considered as those that have been deliberately searched for.
Do these distinctions really matter? They matter in as far as how they are discovered, which can have significant implications for laboratories and clinicians when it comes to the duty to hunt or not. However, once there is a finding, how it was found does not matter; the characteristics of the finding and the implications of returning the finding to the individual likely will not depend on how the finding was discovered. The question that arises is which, if any, secondary or incidental findings should be returned to individuals being sequenced and what principles should guide the decision, particularly in the pediatric context?

\section{Criteria for Returning Secondary/Incidental Findings} to Individuals

It is important to have strict criteria for the return of secondary/incidental findings to individuals undergoing sequencing. Returning a secondary/incidental finding can provide individuals great benefit if it can lead to decreased morbidity and/or morality. But it can also be harmful if it leads to uncertainty, stress, and anxiety because health or wellbeing is not improved, or when further testing is risky and costly. ACCE (Analytic validity, Clinical validity, Clinical utility, and associated Ethical, legal, and social implications) (http://www.cdc.gov/genomics/gtesting/ ACCE/index.htm) is a model developed by the Centers for Disease Control and Preventions' (CDC) Office of Public Health Genomics (OPHG) for evaluating data on genetic tests. Ravitsky and Wilfond [8] further defined analytic validity, clinical validity, and clinical utility within the research context. Using such constructs, a system for "binning" incidental/secondary findings has been proposed in which "highly actionable" (high clinical utility and validity) findings are suggested for return to individuals [9]. The ACMG recommendations for the return of incidental findings [5] are based on a similar assessment of clinical utility and validity pathogenic variants for conditions in which "preventative measures and/or treatments were available" and individuals may be "asymptomatic for long periods of time" are recommended for return.

\section{Recommendations for Returning Secondary/Incidental Findings and the Pediatric Context}

The ACMG has made explicit recommendations for the return of incidental/secondary findings in the clinical context [5]. They recommend that laboratories performing clinical exome/genome sequencing seek and report mutations in a list of "highly actionable" genes, irrespective of age, but excluding fetal samples. A specified list of 56 genes associated with 24 inherited conditions was generated that clinical laboratories should look for and return. The criteria used to generate the list included that the 
conditions have high penetrance, patients may be asymptomatic for a long time, intervention has been clearly demonstrated to be efficacious, there is a high positive predictive value, and the disorder was not otherwise detected by newborn screening. In the initial recommendations, they did not favor soliciting patient preferences as to whether or not to receive the minimum list of incidental findings, although that recommendation has since been rescinded in a subsequent statement [10].

A controversial aspect of the ACMG recommendation is that they did not distinguish consideration of return of incidental/secondary findings in adults from return in pediatrics, and instead recommended that seeking and reporting incidental findings not be limited by the age of the person being sequenced. The statement cited the potential benefit to the future health of the child and the child's parent of discovering an incidental finding where intervention might be possible. This position is in contrast to the standards for predictive genetic testing in clinical genetics that consistently recommend that predictive testing for adult-onset diseases not be offered to children. It is also in contrast to a recent joint statement from the ACMG and the American Academy of Pediatrics that recommends avoiding testing children for known familial mutations for adult-onset disease, on the premise that such testing is inconsistent with the best interests of the child and the child's future autonomy. The ACMG recommendation that the screening process could benefit parents or other family members also contrasts sharply with prevailing justifications of health care for children, in that it proposes testing a child to benefit others.

\section{Ethical Issues Related to the Return of Incidental Findings in Children and Families}

The two important ethical principles in considering return of incidental/secondary genetic findings are "respect for persons" and "beneficence" $[4,11]$. Respect for persons refers to the right of self-determination or autonomy people have the right to make decisions for themselves. Beneficence is the idea of acting in a person's best interests. Both autonomy and best interests are complicated in the case of decision-making regarding children. Clinicians have a duty to act in the best interests of their patients; parents have a duty to act in the best interests of their child. Parents are granted the authority to make decisions that are in the best interests of their child. Children have an evolving capacity for autonomy and an evolving ability to make decisions for themselves. Although children do not have full autonomy, they will have autonomy in the future as adults. The "child's right to an open future" $[12,13]$ refers to the idea that children will have the ability to exercise self-determination in the future, and that the opportunity and right to do so should be preserved for them by their parents making current decisions that will allow children the greatest possibility to make decisions for themselves as adults. In pediatric healthcare decisionmaking, there may be competing concepts: the parent's view of what is in the best interest of the child; the clinician's view of what is in the best interest of the child; the parent's authority to make decisions for their children; the child's future autonomy; the parent's own autonomy; and the parent's view of what is in their own best interest. In addition, how does one define "best interests" [14]?

The ACMG's initial recommendation that laboratories deliberately search for and report the results of 56 genes for highly actionable conditions, without regard to patient preferences, essentially asserted that the best interests of a patient grounded a "duty to prevent harm" and should override patient autonomy [5]. This assertion was in contrast to current medical practice where patients generally have a right to make their own decisions regarding what they do not want to know and a right to decide on receiving medical treatments. The ACMG recently decided to modify their recommendations to allow for patients to opt out of return of secondary findings (their "incidental findings").

However, this discussion did not take into account the pediatric context where there may be limits to the ability of parents to opt out of receiving findings about their child. If there are results for conditions that are serious or lifethreatening, of childhood onset, and are treatable or preventable ("clinically actionable"), then the medical best interests of the child override the parents' autonomy to not know. In fact, parental refusal to receive results of such conditions could be considered child abuse or neglect; just as parents' refusal to treat their child's leukemia would be considered child abuse or neglect. Thus if there was an unexpected "incidental" genetic finding associated with a serious childhood-onset condition that is clinically actionable, parents should not have the option of opting out of receiving such a result. In this case, it would be the clinician's duty to act in the best interest of the child and overrule the parents' right not to know. On the other hand, using newborn screening as a precedent where parents can opt out (though they very rarely do), it seems that after adequate counseling about the potential repercussions, parents should have the option of opting out of the deliberate search for secondary findings, as this falls under the rubric of screening. Thus, context matters. Parents may be able to opt out of a deliberate search for secondary findings, but once there is highly actionable finding, parents should not have the option of receiving such a finding about their child.

It should be noted that there also may be limits on parents' right to know information about their child. The disclosure of results for conditions that are of adult onset may infringe on the children's future right to decide if they want this information. In disclosure of results for conditions that are of adult 
onset but not treatable or preventable, it is in the best interest of the child to protect the child's future autonomy, and this interest overrides the parents' right to know this information. This approach is consistent with the practice of medical genetics for many years. However, when there are results relevant to adult on-set conditions that are treatable or preventable, knowing the result in the child may be beneficial to family members who may be at risk for the condition. Most of the clearly genetic adult-onset, serious/life-threatening, and treatable/preventable conditions are autosomal dominant. A child with the gene variant for one of these conditions likely inherited that variant from a parent. A parent who receives such a sequencing result regarding his/her child is afforded the opportunity to find information important to his/ her own health. In this case, negating the child's future rightnot-to-know or to decide whether to be tested-i.e., violating the child's future autonomy-may be in the best interests of the child, as it may enable the child to have parents who are alive and healthy.

\section{Potential Harms and Benefits of Return of Incidental/ Secondary Findings in Children}

There is little known about the potential benefits and harms of returning secondary/incidental findings in adults or children. Harms may include implications for health care costs; psychological harms (including negative effects on selfimage, esteem, and anxiety); effects on familial relationships (including parental feelings of guilt or blame, stigmatization by family members, and changes in parental expectations including the vulnerable child syndrome); and employment and insurance discrimination [15]. On the other hand, instead of these potential harms, there may actually be benefits, including decreased uncertainty, anxiety or depression; positive effects on self-image and self-esteem; and increased opportunity and resources for individuals to prepare psychologically for the future. Beneficial effects on the family may include decreased parental anxiety, more realistic parental expectations of their child, and facilitation of a family's realistically planning for the future [15]. Little empirical work has been done to assess the true harms and benefits of return of incidental findings in children.

\section{Conclusions}

With the increased feasibility of whole exome/genome sequencing, the focus has turned to harder questions of how to handle the results of sequencing in a manner that maximizes benefits and minimizes harm. Nowhere are these issues more complex than in pediatrics. Yet there is little in the way of empiric data to help guide decisions and recommendations in pediatrics. As more results from sequencing are obtained and returned to patients and families, there will be more opportunities to gather much needed data on the impact on patients, families, and the health care system.

Acknowledgments This work was supported by the National Human Genome Research Institute/National Institutes of Health Grants RC1HG005491, R01HG006615, U19HD077671, U01HG007530, and U01HG006828.

Disclosure I Holm declares no conflicts of interest.

Human and Animal Rights and Informed Consent This article does not contain any studies with human or animal subjects performed by any of the authors.

\section{References}

1. Lander ES, Linton LM, Birren B, et al. Initial sequencing and analysis of the human genome. Nature. 2001;409(6822):860-921.

2. Venter JC, Adams MD, Myers EW, et al. The sequence of the human genome. Science. 2001;291(5507):1304-51.

3. Kohane IS, Masys DR, Altman RB. The incidentalome: a threat to genomic medicine. JAMA 2006;296(2):212-5 doi: 296/2/212 [pii] 10.1001/jama.296.2.212 [doi][published Online First: Epub Date]l.

4. Presidential-Commission-for-the-Study-of-Bioethical-Issues. ANTICIPATE and COMMUNICATE: Ethical Management of Incidental and Secondary Findings in the Clinical, Research, and Direct-to-Consumer Contexts. In: Services USDoHH, ed. Washington, D.C., 2013.

5. Green RC, Berg JS, Grody WW, et al. ACMG recommendations for reporting of incidental findings in clinical exome and genome sequencing. Genet Med. 2013; doi:10.1038/gim.2013.73.

6. Wolf SM, Annas GJ, Elias S. Point-counterpoint. Patient autonomy and incidental findings in clinical genomics. Science. 2013;340(6136):1049-50. doi:10.1126/science.1239119.

7. Burke W, Matheny Antommaria AH, Bennett R, et al. Recommendations for returning genomic incidental findings? We need to talk! Genet Med. 2013;. doi:10.1038/gim.2013.113.

8. Ravitsky V, Wilfond BS. Disclosing individual genetic results to research participants. Am J Bioeth. 2006;6(6):8-17.

9. Berg JS, Khoury MJ, Evans JP. Deploying whole genome sequencing in clinical practice and public health: meeting the challenge one bin at a time. Genet Med. 2011;13(6):499-504. doi:10.1097/GIM.0b013e318220aaba.

10. ACMG. ACMG Updated Recommendation on "Opt Out" for Genome Sequencing Return of Results Secondary ACMG Updated Recommendation on "Opt Out" for Genome Sequencing Return of Results 2014. https://www.acmg.net/docs/Release_ ACMGUpdatesRecommendations_final.pdf.

11. Beauchamp T, Childress J. Principles of Biomedical Ethics. Seventh ed ed. Oxford: Oxford University Press; 2012.

12. Davis DS. Genetic Dilemmas and the Child's Right to an Open Future. Rutgers Law Journal. 1997;23:549-92.

13. Feinberg J. The Child's Right to an Open Future. Freedom and Fulfillment: Philosophical Essays. Princeton: Princeton University Press; 1992. p. 76-97.

14. Ross LF. Predictive genetic testing of children and the role of the best interest standard. J Law Med Ethics. 2013;41(4):899-906.

15. Mand C, Gillam L, Delatycki MB, et al. Predictive genetic testing in minors for late-onset conditions: a chronological and analytical review of the ethical arguments. J Med Ethics. 2012;38(9): 519-24. doi:10.1136/medethics-2011-100055. 